\title{
APONTAMENTOS HISTÓRICOS DA EDUCAÇÃO PROFISSIONAL BRASILEIRA: A LEI DE APRENDIZAGEM No10.097/2000 E SUAS INFLUÊNCIAS
}

Jaqueline Puquevis de Souza

Universidade Estadual do Centro Oeste

\section{RESUMO}

Este artigo é parte de uma pesquisa de mestrado, tendo como objetivo geral compreender a Lei de Aprendizagem n॰ 10.097/2000, buscando desenhar o quadro político dos programas executados no país, sua estrutura, perfil dos alunos e propostas implícitas em suas diretrizes curriculares. A metodologia utilizada pauta-se no materialismo histórico dialético, ilustrando por meio de diário de campo, algumas experiências de jovens aprendizes de uma cidade de interior do Paraná. Ao analisarmos as ações de políticas para juventude e as fontes documentais, para educação profissional, publicadas pelas Organizações Multilaterais e empresariado, identificamos na maioria deles um discurso que racionaliza e justifica as ações adotadas, buscaremos neste estudo evidenciar essa relação.

Palavras-chave: Lei de aprendizagem; organizações multilaterais; empresariado.

\section{HISTORICAL NOTES OF BRAZILIAN PROFESSIONAL EDUCATION: LEARNING LAW No10.097 / 2000 AND INFLUENCES}

\begin{abstract}
This article is part of a master's research with the overall objective of understanding the Braziliam Learning Law n. 10.097/2000, seeking to draw the political framework on the programs implemented in the country, its structure, profile of students in their proposals and implicit curriculum guidelines. The methodology is guided in dialectical and historical materialism, illustrating by means of a field diaries, a few lines wrote by young apprentices of a city from Paraná state. By analyzing actions from policies for youth and documentary sources, to professional education, published by the WHO (Word Health Organization), and businessmen, most of them identified in a discourse that rationalizes and justifies the actions taken, this study will seek to demonstrate this relationship.

Keywords: Learning Law; World Health Organization; businessmen.
\end{abstract}

\section{Introdução}

As primeiras regulamentações da Lei de Aprendizagem, surgem na década de 1940, sancionando a entrada do adolescente no mercado de trabalho. Com a crescente industrialização e a necessidade de qualificação da mão de obra, para as indústrias que aqui se estabeleciam, é criado pelo Decreto-Lei 4.048 de 22 de janeiro de 1942, o Serviço Nacional de Aprendizagem Industrial (SENAI), tendo como principais fundadores Euvaldo Lodi e Roberto Simonsem, que eram respectivamente presidentes da Confederação Nacional da Indústria (CNI) e Federação das Indústrias do Estado de São Paulo (FIESP). Esta parceria estabelecida com o então presidente Getulio Vargas, compartilha a responsabilidade do empresariado brasileiro na criação de um novo modelo em Educação Profissional. Em 1946, nasce o Serviço Nacional de Aprendizagem Comercial (SENAC), 
para atender as demandas do setor do comércio. Os dois sistemas tiveram êxito na proposta inicial e são fortes entidades de formação profissional até os dias atuais. Suas ações são financiadas com $1,5 \%$ sobre a folha de pagamento dos recursos humanos, de todas as indústrias no caso do SENAI, e o mesmo, sobre segmentos do comércio no caso do SENAC. Em 16 de julho de 1942, é sancionado o Decreto-Lei n॰4.481, determinando por meio de seu art.1॰ que:

Os estabelecimentos industriais de qualquer natureza são obrigados a empregar e matricular nas escolas mantidas pelo Serviço Nacional de Aprendizagem (SENAI), um número de aprendizes equivalente a $5 \%$ no mínimo e $15 \%$ no máximo, dos operários existentes em cada estabelecimento e cujos ofícios demandem formação profissional (BRASIL, 1942, s.p).

Mas, foi em um de maio de 1943, que se formalizou a obrigatoriedade da participação dos menores, nos cursos de aprendizagem que ingressassem no segmento industrial brasileiro. Nesta regulamentação, foi determinado o registro em carteira, e remuneração aos menores de no mínimo meio-salário. Estes acordos, na década de 40, marcaram estratégias para promoção da industrialização, "[...] reprodução ampliada do capital, via adestramento e exploração da força de trabalho infanto-juvenil" (BUIAR e GARCIA, 2008, p. 2).

A Lei Aprendizagem, determinava a contratação de jovens com idade mínima de 12 anos, que tivessem concluído o ensino primário, em boas condições físicas e mentais e não apresentassem nenhuma moléstia contagiosa. A prioridade das vagas seria direcionada aos filhos dos trabalhadores industriais, órfãos e posteriormente parentes dos mesmos. Em relação aos conteúdos para os currículos propostos na formação, a orientação era que apresentassem disciplinas e práticas essenciais para cada ofício, organizados em cursos de aprendizagem. Em relação à carga horária dos cursos, ficaria a cargo dos estabelecimentos industriais sua determinação, mas deveriam ser executadas dentro do horário de trabalho dos aprendizes e com frequiência obrigatória. Ao término do contrato os alunos receberiam uma carta de ofício, ficando a cargo das próprias indústrias a fiscalização das atividades ministradas pelo SENAI (BRASIL, 1942).

Em 10 de janeiro de 1946, pelo Decreto-Lei 8.622, são estabelecidas novas propostas para Lei de Aprendizagem, mas direcionados, agora, para o segmento comercial. No art. 1० é exposta a obrigatoriedade da contratação de menores aprendizes a todo segmento comercial, acima de nove funcionários, devidamente matriculados nos cursos de aprendizagem do SENAC. O perfil, os conteúdos e os cursos, mantém a mesma linha determinados para o SENAI, apenas direcionados agora para o comércio. Esta foi à primeira versão da Lei de Aprendizagem (BRASIL, 1946).

A segunda publicação da Lei de Aprendizagem, ocorreu em 2000, devido a profundas transformações econômicas nos anos 90, que afetaram o mercado de trabalho jovem no país. Segundo Pochmann (2000), os postos de trabalhos mais evidentes eram as ocupações autônomas, mas que mantinham formas flexíveis e diferentes do trabalho assalariado, assim, eram instáveis e poderiam não propiciar o desenvolvimento profissional dos jovens, nem garantiam os direitos assegurados pela legislação trabalhista.

O autor externa que, a redução do trabalho assalariado foi drástica, atingindo 1,8 milhões de jovens nesse período, trazendo uma exposição dos fatores que contribuíram nesse cenário. O primeiro fator, seria desemprego por inserção, ou seja, a falta de experiência profissional, que gera dificuldades de obtenção do primeiro emprego. $\mathrm{O}$ segundo seria o desemprego recorrente, que consiste em ocupações temporárias, sem 
estabilidade, o que obriga esses jovens a mudarem constantemente de função. O terceiro, seria o desemprego de reestruturação, ocasionado pelas empresas privadas, por dois motivos: o fechamento de empresas nacionais, e os novos modelos de produção e organização de trabalho, que exigem um quadro de pessoal menor. O último seria o desemprego por exclusão, englobando aqueles que permanecem na condição de sem emprego, por falta de medidas adequadas que contribuam para o aumento de vagas.

Buscando o aumento de vagas formais para os jovens, que atendessem um mercado profissional cada vez mais exigente, por meio do aumento de mão de obra qualificada, o governo brasileiro reformula no ano de 2000, a Lei de Aprendizagem 10.097 determinando nesse momento, que:

\begin{abstract}
"Os estabelecimentos de qualquer natureza são obrigados a empregar e matricular nos cursos dos Serviços Nacionais de Aprendizagem um número de aprendizes equivalentes a 5\% (cinco por cento), no mínimo e $15 \%$ (quinze por cento), no máximo, dos trabalhadores existentes em cada estabelecimento, cujas funções demandem formação profissional"( art. 429 CLT ).
\end{abstract}

A nova Lei do Aprendiz, amplia a execução dos programas, para as Organizações não-governamentais (ONGs) ${ }^{1}$. Nessa nova publicação é mantida a aprendizagem metódica industrial, entendida como "[...] atividades teóricas e práticas, metodicamente organizadas em tarefas de complexidade progressiva desenvolvidas no ambiente de trabalho", segundo o art. $6^{\circ}$ do decreto 5.598, de $1 \circ$ de dezembro de 2005.

Para o Estatuto da Criança e do Adolescente (ECA), no art. 62, "a aprendizagem é a formação técnico-profissional ministrada ao adolescente ou jovem segundo as diretrizes e bases da legislação de educação em vigor, implementada por meio de um contrato de aprendizagem". No contrato de aprendizagem é estipulado, um prazo máximo de dois anos, com objetivo de formação profissional do aprendiz, que poderá ser efetivado ou não pelas empresas empregadoras. A idade mínima dos jovens passa de 12 para 14 anos. A responsabilidade da empresa é de inscrever o jovem em um programa de aprendizagem, que proporcione uma formação para o desenvolvimento físico, moral e psicológico. Esta atividade deve ser remunerada, de acordo com o salário mínimo - hora, ou superior, dependendo da convenção ou acordo coletivo da categoria. O art. 428 da CLT traz como atribuição do aprendiz, executar com zelo e diligência suas tarefas.

A última atualização da Lei de Aprendizagem ocorreu recentemente durante a elaboração desta pesquisa. Foi sancionada em novembro de 2013, a Portaria 723/12, a qual não poderia deixar de citar nesse estudo. As principais modificações ocorreram nas cargas horárias dos cursos, que será explanada logo abaixo na configuração dos programas. A segunda modificação é relativo a supervisão dos programas e das entidades formadoras, que agora ficam sob responsabilidade da Secretaria de Políticas Públicas de Emprego (SPPE), que deverá basear-se na Classificação Brasileira de Ocupações ${ }^{2}$ para verificar se os programas atendem aos objetivos dos ofícios que se propõe a ensinar. Os programas de aprendizagem deverão ser elaborados conforme o Catálogo Nacional dos Programas de Aprendizagem $^{3}$. Este Catálogo é uma das inovações, sua meta é direcionar a elaboração dos programas de aprendizagem profissional, especificando os requisitos de idade, escolaridade, carga horária dos cursos, complexidade técnica da formação e descrição do ofício. Quem elabora os programas são as entidades formadoras, mas com supervisão, orientação e aprovação da SPPE. Também são estabelecidas novas diretrizes que serão explanadas detalhadamente no decorrer desse capítulo. 


\section{O jovem aprendiz e a configuração dos programas de aprendizagem}

Na nova Lei de Aprendizagem, o aprendiz é o jovem entre 14 e 24 anos, que esteja matriculado e freqüentando a escola, caso não tenha terminado o ensino médio, na busca de seu primeiro emprego. A prioridade é o atendimento de jovens em situação de vulnerabilidade social, ou seja, vindos de famílias menos favorecidas. A crise no mercado de trabalho nos anos 90, possivelmente aumentou os fatores de risco e vulnerabilidade da juventude. Com a redução de emprego e renda das famílias brasileiras nesse período, muitos jovens se viram obrigados a contribuir financeiramente nas despesas do lar, acabando por afastarem-se da escola. Além de atividades sem carteira assinada "[...] atividades inaceitáveis (trabalho escravo, insalubre, perigoso, prostituição infantil, tráfico de drogas, crime organizado etc)" (POCHMANN, 2000, p.24), aumentaram na realidade brasileira, reforçando a terminologia.

Em relação à jornada de trabalho, o art. 18 prevê que a duração do trabalho do aprendiz não excederá a seis horas, ou oito horas para aprendizes que já tenham concluído o ensino fundamental, mas computadas nesse período, as horas destinadas a aprendizagem teórica nos cursos em que estão inscritos.

Os programas de aprendizagem devem adotar a partir de 2014, as diretrizes e parâmetros para seu funcionamento, publicadas na Portaria 723/12. Toda entidade formadora inscrita no Cadastro Nacional de Aprendizagem ${ }^{4}$, que apresente projetos de cursos pautados nessa Portaria, poderão ter seus processos validados. Esse cadastro também deverá ocorrer no Conselho Municipal da Criança e do Adolescente. Para que os programas sejam aprovados, deveram ser seguidas as seguintes orientações:

Art. $5^{\circ}$ A inscrição do programa de aprendizagem deve ser feita nos moldes do art. $3^{\circ}$ desta Portaria e a entidade deve fornecer, no mínimo, as seguintes informações:

I - público participante do programa de aprendizagem, com máximo de aprendizes por turma, perfil socioeconômico e justificativa para seu atendimento;

II - objetivos do programa de aprendizagem, com especificação do propósito das ações a serem realizadas e sua relevância para o público participante, a sociedade e o mundo do trabalho;

III - conteúdos a serem desenvolvidos, contendo os conhecimentos, habilidades e competências, sua pertinência em relação aos objetivos do programa, público participante a ser atendido e potencial de aplicação no mercado de trabalho;

IV - estrutura do programa de aprendizagem e sua duração total em horas, em função do conteúdo a ser desenvolvido e do perfil do público participante, contendo:

a) definição e ementa dos programas;

b) organização curricular em módulos, núcleos ou etapas com sinalização do caráter propedêutico ou profissionalizante de cada um deles;

c) respectivas cargas horárias teóricas e práticas, fixadas na forma dos $\S \S$ $2^{\circ}$ e $3^{\circ}$ do art. 10 desta Portaria, ou em exceção específica constante do CONAP relativa à ocupação objeto do programa de aprendizagem; e d) atividades práticas da aprendizagem desenvolvidas no local da prestação 
dos serviços, previstas na tabela de atividades da CBO objeto do programa; (BRASIL, 2012).

A carga-horária dos programas, deverá ter no mínimo de $40 \%$ de atividades teóricas, nos cursos de 400 horas, ou 50\% nas demais cargas horárias. Os conteúdos e material utilizado ficam sob a responsabilidade da entidade formadora, mas devem contemplar "conteúdos e habilidades requeridas para o desempenho das ocupações objeto da aprendizagem, preferencialmente organizados conforme Portaria 723/12 e regulação inicial e continuada de trabalhadores pelos Arcos Ocupacionais" (BRASIL, 2012, s.p). Estes $A r \cos ^{5}$ descrevem as denominações e atribuições das vagas, agrupando as ocupações com base técnica semelhante.

A principal modificação nesta nova proposta é a permanência do jovem aprendiz em 80 horas teóricas de formação contínua nas entidades formadoras, para capacitação antes do início de sua prática. O objetivo é possibilitar segurança e aquisição de conhecimentos aos jovens, favorecendo as empresas na hora da contratação. Podemos dizer que este é um avanço na Lei da Aprendizagem, pois muitos jovens tinham dificuldades de iniciar suas atividades práticas, sem orientações adequadas e acabavam tendo alguns problemas nas empresas contratantes. O relato abaixo ilustra uma dessas situações, observadas no diário de campo de nossa prática profissional:

No começo tive muitas dificuldades de relacionamento, pois me sentia perdida na minha função de crediarista, tinha medo de me aproximar das pessoas, por não saber nada. Mas nesta empresa, eles conheciam a lei do aprendiz e me ensinaram muito (APRENDIZ 01, 2013, COMUNICAÇÃO ORAL).

Aprender a lidar com material de construção é muito complicado, isto só se aprende com o tempo, neste trabalho não podemos não responder o cliente. No começo foi difícil, não sabia nada, mas a empresa que estou tem me ajudado e explicado (APRENDIZ 02, 2013, COMUNIÇÃO ORAL).

Outro avanço nessa Portaria é a contratação de corpo docente próprio. Nesta pesquisa, discorremos que muitos instrutores são contratados para ministrar os módulos independentes, sem o mínimo de treinamento, para que possam conhecer os verdadeiros objetivos da Lei de Aprendizagem. Nesta portaria as entidades formadores possuem um Termo de Compromisso, que sugere uma proposta para a oscilação e falta de qualificação adequada do corpo docente, além do investimento na e estrutura física:

I - adequação da proposta pedagógica aos princípios e diretrizes desta Portaria;

II - existência de quadro técnico-docente próprio, na localidade em que se desenvolverá o programa, devidamente qualificado; e

III - estrutura física e equipamentos disponíveis condizentes com os objetivos da formação profissional.(BRASIL, 2012, s.p).

Algumas modificações coerentes foram colocadas teoricamente nessa proposta, resta- nos se serão cumpridas pelas entidades formadoras, com intuito a formação para trabalho como um princípio educativo. 


\section{Dados e ações atuais sobre a lei de aprendizagem}

Em 2013, o Ministério do Trabalho e Emprego publicou alguns dados sobre a Lei de Aprendizagem. Entre 2005 a 2013, participaram dos programas de aprendizagem 1,3 milhão de jovens. No ano de 2013 entre janeiro a maio, foram disponibilizadas $142 \mathrm{mil}$ vagas para os aprendizes, sendo que 85 mil vagas eram para o setor administrativo. Em 2012, foram inseridos cerca de 286 mil jovens, no mercado de trabalho via Lei de Aprendizagem.

Segundo informações do MTE (2013), atualmente a Lei de Aprendizagem tem o potencial de oferecer 1,2 milhão de oportunidades de trabalho para os jovens no Brasil, se todas as empresas privadas cumprirem com suas determinações. Contando com a parceria das empresas públicas esse número poderia chegar a 1,6 milhões de vagas. Infelizmente em um levantamento no ano de 2010, apenas $25 \%$ desse montante havia sido ocupado. Aqui encontramos um ponto interessante em nossa pesquisa, as oportunidades de trabalho via Lei de Aprendizagem existem, mas dos 3,6 milhões de alunos matriculados no primeiro ano do ensino médio, apenas 1,8 milhão de jovens, buscam os cursos de aprendizagem disponíveis.

A pesquisadora do IPEA Enid Rocha (2013), aponta duas probabilidades da pouca procura dos cursos. A primeira seria a baixa qualificação educacional dos aprendizes, que não conseguem acompanhar os cursos de aprendizagem, ou que entram nos programas, mas acabam desistindo por dificuldades ou falta de interesse, a segunda seria a restrita oferta de variabilidade de cursos, muito direcionadas as realidades de cada local, por exemplo, em cidades menores os cursos existentes se limitam a aprendizagem comercial, que encaminha os aprendizes para vagas do comércio, farmácias e supermercados, não possibilitando a escolha do jovem segundo suas aptidões. A falta de conhecimento sobre a relevância da Lei de aprendizagem, pelos empresários, também é uma colocação apontada por ela. Esta problemática pode ser ilustrada observação do diário de campo colhido pelo depoimento de dois aprendizes, de umas das instituições formadoras de minha prática profissional:

Eu iniciei lá com alguns problemas, pela empresa não conhecer a lei do aprendiz. Ai eu vim aqui no instituto que estudo. Contei o que tinha acontecido pro meu gerente. Ele é uma pessoa gente boa e conforme foi conhecendo a lei melhorou, ele não tinha entendido que o aprendiz não pode fazer hora extra, carregar peso, mas eles achavam que eu estava fazendo corpo mole, mas não era isso, eu só queria seguir a lei. Conforme eles foram aprendendo eles foram aceitando e se adaptando. Eu gosto muito da empresa. Eu faço o curso de aprendizagem em Administração e no começo me colocaram pra descarregar tijolos, isso me deixou muito bravo, mas fui conversar. Então iniciei como conferente e hoje sou auxiliar administrativo, e por essa minha atitude estou muito bem aqui, querem me efetivar (APRENDIZ, 03, 2012, COMUNICAÇÃO ORAL).

No começo o pessoal não entendia a lei do aprendiz, diziam: porque este piá não vem de manhã trabalhar. Eles não conheciam o programa e eu sabia de fofocas de funcionários que não gostavam de mim por isso. 
Falavam assim: esse piá ganha igual a nós e não trabalha. Ai minha chefe fez uma reunião e explicou. As pessoas não conhecem a lei de aprendizagem e fica muito complicado pra gente, acho que a maior dificuldade foi essa, eles não conseguem entender a diferença de estagiários e aprendizes (APRENDIZ 04, 2013, OMUNICAÇÃO ORAL).

Estas falas demonstram exatamente o desconhecimento por parte dos empresários e funcionários, sobre a Lei de Aprendizagem e seus objetivos. Na aprendizagem do ofício, é obrigatório aliar a atividades teóricas e práticas, adequadas aos programas que os jovens estão inscritos. Algumas empresas contratam aprendizes apenas para cumprirem as determinações legais e acabam expondo os menores a atividades insalubres e proibidas. Nestes casos ilustrados, trata-se de jovens com total conhecimento de suas atribuições e com um perfil mais ousado, que mobilizaram a empresa para apresentar a Lei de Aprendizagem, mas em muitos casos os menores, acabam se expondo a executarem todas as tarefas que lhe são repassadas, além de sofrerem com as rotulações que the são atribuídas.

Atualmente uma instituição que tem lutado para fortalecer e divulgar a Lei de Aprendizagem é a Rede Pró-Aprendiz (RPA). Formada em 2000, pela união das entidades formadoras, nasceu após a Fundação Pró-Cerrado de Goiás, que trabalha para inclusão social dos jovens através de programas de aprendizagem, receber o prêmio de Melhor Plano de Negócio Social, pelas Consultorias Americanas Mackinsey e Ashoka. Seu principal objetivo é fortalecer as ações da Lei de Aprendizagem e seus respectivos programas. Em junho de 2013, realizou o I Seminário Lei do Aprendiz: Educação e cidadania empresarial na prática, que buscou inserir a Lei de Aprendizagem como uma política pública para juventude. Seu parceiro foi o Unibanco, tendo como público: empresários, MTE, gestores públicos, organizações sociais executoras dos programas de aprendizagem. Os temas discutidos no evento foram o cumprimento da Lei de Aprendizagem, tendo em vista sua relevância para o desenvolvimento socioeconômico do país. Os palestrantes ainda trouxeram alguns dados aproximados da inserção dos jovens no mercado de trabalho, delimitando um número de 8 milhões de oportunidades atingidas até 2015, se os segmentos públicos e privados, cumprirem corretamente a Lei 10.097. A primeira edição do Seminário foi realizada estrategicamente em Florianópolis, Santa Catarina, pois é o estado que possui um baixo índice de empregabilidade formal dos jovens, até 2013 apenas 18\% das vagas direcionadas aos jovens aprendizes foram preenchidas.

\section{O Plano Nacional de Aprendizagem}

Mesmo com as alterações na Lei de Aprendizagem e a fiscalização do MTE, os índices de pobreza e desemprego entre os jovens brasileiros, ainda são alarmantes, como já expostos nessa pesquisa. Diante desse quadro o MTE, juntamente com a sociedade civil organizada e o poder público, aprovou o Plano Nacional de Aprendizagem (PNAP), buscando fortalecer ações de estímulo a aprendizagem profissional aos jovens e adolescentes. Nesta proposta, algumas ações estão sendo realizadas para melhorias nos programas de aprendizagem. A primeira ação do PNAP foi criar programas de aprendizagem na administração pública e empresas prestadoras de serviços nesses segmentos, que anteriormente não estavam inclusas. Isto tem ampliado as oportunidades: 
O propósito é que se realize um processo seletivo público, estrategicamente orientado para os adolescentes de políticas públicas em plena expansão pelo governo federal, como os resgatados do Programa de Erradicação do Trabalho Infantil (PETI), quando em idade entre 14 e 17 anos, os beneficiários do Programa Bolsa Família (PBF), ou ainda os adolescentes submetidos a medidas socioeducativas que encontram muito mais dificuldades para uma oportunidade no meio privado (CLEMENTINO, 2013, 48).

Neste ponto gostaríamos de ilustrar que essa é uma ação que tem possibilitado resultados positivos para muitos jovens, que não conseguiam postos de trabalho em outros segmentos. O relato abaixo demonstra a fala de um jovem aprendiz de 19 anos de idade, do curso de aprendizagem em administração, efetuado por uma ONGs, que a encaminhou para o setor judiciário de uma cidade do interior do Paraná:

Tenho vergonha de assumir, mas parei várias vezes na delegacia por vandalismo e briga, agora com meus colegas de trabalho, aprendi que nem sempre a razão é minha, eles fizeram me conhecer pessoalmente. Estou terminado meu contrato de dois anos. No trabalho, estou aprendendo muito, estou conhecendo jurisdição. Mas quero conciliar com a psicologia, que acabei de passar e consegui bolsa. Eu quero me especializar em reabilitação e drogas, quero mexer com isso, tenho parentes que trabalham na PIG e conheço esta realidade. Com o jovem aprendiz tive a oportunidade de entrar na justiça no setor criminal e aprendi muita coisa, como: penas comunitárias, audiências, fico analisando, olhando os réus e gosto bastante. Ali dentro convivo com pessoas que viraram uma família, meus chefes são um pai e uma mãe, me espelho no jeito deles resolverem os problemas e levarem a vida. Eu era muito abafada e eles me ensinaram que devo terminar o que começo, e não parar por eu quero. Eles me ajudaram a ser forte, a não descontar minha raiva nos outros, a não chegar de cara fechada (APRENDIZ 05, ONG, 2012, COMUNICAÇÃO ORAL).

Esta fala demonstra que os programas de aprendizagem apesar de suas limitações, podem ser muito relevantes na vida de muitos jovens. Além das práticas aprendidas nos ambientes laborais, os jovens podem ter a oportunidade de um convívio social pleno, que os levem a se desenvolverem como pessoas. Especificamente nesse caso, a jovem além de melhorar sua qualidade nas relações sociais, aprender sobre suas possibilidades e restrições, finaliza seu contrato com a inserção na faculdade, pelo incentivo do departamento.

Continuando, sobre as ações do PNAP, podemos enfatizar que ele tem sugerido, a padronização de ofertas dos programas e currículos, qualidade técnico-pedagógica e a constante reformulação dos cursos, para que se tornem condizentes com as ofertas de trabalho que o mercado de trabalho tem oferecido. Atualmente o PNAP tem veiculado na mídia informações e propagandas, para divulgar a Lei de Aprendizagem e sua relevância para o desenvolvimento social e econômico do país.

\section{O empresariado e a Lei de Aprendizagem}

Buscando o aumento da competitividade industrial para o desenvolvimento econômico do país, o empresariado brasileiro, adepto das propostas da Reforma do Estado e do discurso da crise da educação, tem atuado como protagonista nas articulações das 
políticas educacionais. Assim, em conjunto com Oms, eles são fortes aliados do capital e os principais agentes financiadores para a concretização das ações que acontecem, conseqüentemente, traçam os ditames que deverão ocorrer, buscando nesta relação de troca, atender os seus próprios interesses. " $\mathrm{Na}$ verdade os empresários peticionam a participação ativa nas decisões ativas referentes aos destinos na educação brasileira, incluindo a participação nas esferas de decisão no Ministério da Educação e até mesmo no cogerenciamento das escolas" (MELO, 2009, p.908).

Em nossa pesquisa, pudemos perceber as determinações sofridas pela educação profissional, num processo desencadeante de uma lógica cíclica: as políticas para juventude em educação profissional com orientações das OMs, influenciam as ações e determinações do empresariado brasileiro, junto ao Estado, que gestam as diretrizes do funcionamento dos cursos oferecidos no Brasil. Nesta sessão começamos nossas discussões através da análise dos discursos e ações do empresariado brasileiro, nas práticas da Lei de Aprendizagem e na educação profissional. Como a Lei de Aprendizagem obrigada este segmento a contratar aprendizes, são eles atualmente a principal fonte formal, de inserção dos jovens no mercado de trabalho brasileiro.

Os dirigentes das políticas para educação e da indústria, começaram a fazer aproximações da escola com os setores produtivos, buscando dinâmicas gerenciais muito semelhantes. "O padrão ideal de aprendizagem é aquele no qual o educando desenvolva as habilidades de aprender a aprender e apreender a fazer "(OLIVEIRA, 2005, p.11). Os textos produzidos pela principal instituição representativa do setor industrial no Brasil, a Confederação Nacional das Indústrias $(\mathrm{CNI})^{6}$, demonstram esse ideal. A indústria, que não tem interesse em diminuir seus lucros e aumentar de postos de trabalho, apóia a idéia de apenas treinar os trabalhadores.

Estas determinações do empresariado brasileiro vão ao encontro das propostas das OMs, como a educação profissional aligeirada, que adéqüe a aprendizagem para novas tecnologias. Para Melo (2009), os documentos da CNI, trazem fragmentos de uma proposição de uma educação básica sólida, que facilite a aquisição para o aprendizado desses novos conhecimentos, pois na formação profissional, não pode ser despendido muito tempo de capacitação. A CNI adere às filosofias do BM, BIRD e CEPAL, de que a educação é a principal forma de reverter a situação financeira e social de sua população, desde que esteja articulada ao desenvolvimento e competitividade, para isso:

A indústria deseja ser eficiente, competitiva e inserida em uma sociedade marcada pela melhoria dos indicadores sociais e redução dos desequilíbrios pessoais e espaciais de renda. Atuar, simultaneamente, sobre os problemas de eficiência e eqüidade é o grande desafio da sociedade brasileira. Os caminhos para se atingir este objetivo passam, necessariamente pela elevação da produtividade, pelo aumento da eficácia dos gastos sociais (em especial, saúde e educação) e manutenção de uma trajetória de crescimento sustentável. É a compreensão da indústria em que processos de ajustes centrados, não são suficientes para estruturar uma nova direção estratégica (CNI, 1994, p.6).

Mas existe uma contradição explicíta, quando a CNI refere-se à eficácia nos gastos sociais, não está instigando o aumento do Estado em investimentos nestas áreas, ao contrário, para ela o investimento público na área social, gera altos impostos, impossibilitando que as indústrias consigam competir com a produção estrangeira. Por isso, sempre foram a favor da privatização e da reforma do Estado, do ideário neoliberal, para melhorias em seu próprio favor. "Percebe-se o perfil do trabalhador que se quer 
formar para os interesses da burguesia industrial: um trabalhador que não se compromete como elemento de classe, mas apenas consigo mesmo e com a empresa" (MELO, 2009, p.897).

Como exposto no tópico anterior, às empresas estão diretamente ligadas aos programas de aprendizagem, pois são as intermediadoras das práticas dos aprendizes, junto à formação pelo Sistema S. Atualmente, estas entidades formadoras, representam os setores produtivos como: indústria, comércio, transporte, agricultura, cooperativas e outros. E seu orçamento é controlado pela própria CNI, no montante de 8 bilhões de reais, provindos dos $1,5 \%$ das folhas de pagamento das empresas.

As contradições nas propostas políticas, econômicas e educacionais das entidades do Sistema S são evidentes deste a criação do SENAI . Não se pode negar que é um sistema dotado de alta legitimidade no Brasil, com escolas espalhadas em todos os estados e uma estabilidade de mais de 60 anos. Segundo Cunha (2000) o SENAI, por exemplo, deveria ser uma instituição pública pela sua constituição determinada pelo decreto-lei 1946, 1967 e 1988, também respaldado nas Leis de Diretrizes e Bases da Educação Nacional (1961 e 1966), mas se analisarmos a gestão de recursos é visivelmente uma instituição privada, mostrando o cooporativismo do Estado novo. Na direção do SENAI, como nas outras entidades, ficam evidentes estes traços, através de seu gerenciamento pela:

A Confederação Nacional das Indústrias, mais as federações estaduais de sindicatos patronais que dirigem a entidade, escolhem seus diretores e determinam a política a ser seguida. Na composição do Conselho Nacional e dos conselhos regionais, a participação mínima do Estado pode ser assinalada: ao lado dos presidentes das federações ou sindicatos patronais, estão dois representantes do governo, um do Ministério do Emprego e outro do Trabalho (CUNHA, 2000, p.45).

O problema é que estas instituições têm personalidade jurídica de direito privado, mas não se enquadram como fundações ou associações, ficando obscuro sua adequação a uma Administração Indireta ${ }^{7}$. Outro problema é que estas entidades "não prestam serviço público delegado pelo Estado, mas atividade privada de interesse público (serviços não exclusivos do Estado); exatamente por isso, são incentivadas pelo Poder Público" (PIETRO, 2010, p. 505). Entidades como estas possuem uma série de privilégios perante o Estado, as exigências ficam apenas focalizadas na fiscalização estatal da contratação de pessoal e prestação de contas de suas atividades.

Para o empresariado as propostas de Reforma do Estado percebidas no âmbito da qualificação profissional pelo setor público-não estatal, fortalecem seu segmento. $\mathrm{O}$ empresariado reconhece a ineficiência do Estado entrando como protagonista nas ações, através da filantropia e das questões sociais. Viriato (1997) comenta que a filantropia empresarial não se preocupa apenas com a solidariedade, mas articula seus propósitos em benefício do próprio capital, capacitando mão de obra para aumento da produtividade através do desenvolvimento da força de trabalho. Nesta transmissão de ações estatais uma grande parte dos ganhos fiscais, deve ser repassada a um fundo público internacional, impedindo o Estado de investir mais nos problemas sociais, fortalecendo ainda mais as parcerias com a sociedade civil e o empresariado.

$\mathrm{Na}$ proposta de responsabilidade social das empresas existe uma constante problemática, esta parceria encobre através de seus feitos a "exploração do trabalho, negando o conflito de interesses de classes" (VIRIATO, 19997, p.82). As empresas 
atuando efetivamente na responsabilidade social do Estado o reduzem como agente de ações sociais e responsável pelos benefícios do trabalhador. O problema é que:

\begin{abstract}
A possibilidade dos trabalhadores intervirem, criticarem,polemizarem, interferirem pelo comum - ocorre na esfera pública estatal; portanto, o público estatal tem sido o espaço do político, da ação em prol do bem comum coletivo. Nele os sujeitos sociais procuram exercer, na disputa política, o poder de interferência e decisão"(VIRIATO, 1997, p.82).
\end{abstract}

Documentos publicados pelo Banco Mundial como: Reformas Econômicas e Trabalhistas na América Latina e Caribe de 1995, já indicavam o modelo brasileiro adotada pelo SENAI, como referência de formação aos demais países. No âmbito político brasileiro cada vez mais as empresas não-estatais ganham credibilidade, sobre a ineficiência do Estado que deveria ser o espaço de luta pelos direitos sociais.

\title{
As OMs e a Lei de Aprendizagem: A Organização Internacional do Trabalho
}

A Organização Internacional do Trabalho (OIT) "é a agência das Nações Unidas que tem por missão promover oportunidades para que homens e mulheres possam ter acesso a um trabalho decente e produtivo, em condições de liberdade, equidade, segurança e dignidade" (OIT, 2013, s.p). O termo trabalho descente, cunhado em 1999, representa e abrevia toda a missão da OIT exposta na frase anterior, além de ser um dos objetivos estratégicos na busca da diminuição de desigualdades sociais, ou "trabalho produtivo adequadamente remunerado, exercido em condições de liberdade, equidade e segurança, capaz de garantir uma vida digna" (MTE, 2013).

Em 2003, a OIT, formalizou com o governo brasileiro o compromisso de desenvolverem ações conjuntas de políticas para juventude. Para Clementino (2013), a Aprendizagem respaudada pela Lei 10.097, através de seus programas é vista como um dos mecanismos mais eficientes para o desenvolvimento de ações para o mercado de trabalho juvenil para o trabalho descente. A determinação desta OM foi tão incorporada no Brasil, que em 2006 tornou-se tema da Agenda Nacional de Trabalho Descente (ANTD) e em 2012, foi Agenda Nacional de Trabalho Descente para Juventude (ANTDJ), aonde foram estabelecidas quatro prioridades:

\footnotetext{
i) mais e melhor educação; ii) conciliação dos estudos, trabalho e vida familiar; iii) inserção ativa e digna no mundo do trabalho; e iv) o diálogo social -, podem-se identificar, no instituto legal da aprendizagem profissional, os elementos que justificam seu caráter de trabalho decente"(CLEMENTINO, 2013, p.47).
}

No primeiro item: mais e melhor educação, foi discutido o cumprimento da Lei de Aprendizagem, o tempo do contrato e a vinculação do programa à freqüência obrigatória na escola, para aqueles que não terminaram a educação básica. Outra preocupação dessa agenda é a forma como os cursos de aprendizagem devem ocorrer. Notamos que as colocações feitas teoricamente pelo MTE, são extremamente relevantes, pois defendem que a formação produtiva do aprendiz, não deve sobrepor a formação qualitativa, e a saída da escola para o mercado de trabalho, deve ocorrer de forma gradual, para atender os verdadeiros objetivos da aprendizagem. Em nossa pesquisa mesmo com um caráter 
bibliográfico, tivemos a oportunidade de ouvir vários depoimentos de jovens que estão atuando em empresas em contratos de aprendizagem.. Esse acesso foi possível, pois em minha experiência profissional fui instrutora do Sistema $S$ e por estar pesquisando a Lei de Aprendizagem, muitos alunos da Universidade aonde atuo e que trabalham como aprendizes, compartilham suas experiências. Infelizmente, a maioria das empresas ainda não conhece a proposta da Lei de Aprendizagem, que poderia ser uma grande aliada na preparação de bons profissionais. O desenvolvimento pleno do aprendiz por meio de uma formação metódica de qualidade, aliando às atividades práticas, convivência social no espaço de trabalho, podem trazer profissionais mais capacitados profissionalmente e pessoalmente, o que gera muitos benefícios para o empresário, pois um funcionário pleno e satisfeito não gera rotatividade .

A proposta da aprendizagem, é de formar e lapidar os aprendizes de acordo com as necessidades do mercado, mas em um ritmo adequado, que atinja todas as possibilidades de aprendizagem do jovem. Na maioria dos discursos dos aprendizes, que ouvimos no decorrer dessa pesquisa, existe uma prática um pouco contraditória ao que a Lei propõe. Muitos desses jovens relatam que os empresários tecem críticas ao afastamento dos aprendizes de suas práticas, para realização dos módulos teóricos; outro problema é a jornada de 6 horas diárias, criticada pelos próprios colegas de trabalho, que acreditam que o aprendiz não poderia ter "privilégios" de cargas horárias menores, isso pela falta de explicação sobre o programa. A "sociedade ainda não tem conhecimento da importância de um programa de aprendizes. Tanto o estágio quanto a aprendizagem são oportunidades de inserção, mas a lei de aprendizagem ainda permite uma qualificação profissional" (ROCHA, 2013,s.p ). Esta é a segunda prioridade do ANTDJ, a conciliação dos estudos, trabalho e família.

Na quarta proposta: diálogo social deve ser permeados as relações de trabalho, e uma das formas é o trabalho descente, como o proposto pela Lei de Aprendizagem. Para isso foi criado em 2008, o Fórum Nacional de Aprendizagem Profissional, que tem buscado mobilizar todos os segmentos da sociedade civil e organizada, para conscientização dos programas de aprendizagem:

É verdade que o fórum nacional, já replicado na grande maioria dos estados, visando ao equacionamento de questões que necessitam de articulação em nível local, ainda carece de uma participação mais ativa dos próprios aprendizes para que se constitua em um verdadeiro espaço de diálogo social. Não se tem dúvida de que programas de aprendizagem propiciam a reflexão do aprendiz sobre as relações sociais e corporativas em que está provisoriamente envolvido; e que esse jovem tem oportunidade de conviver com diversas categorias profissionais, além da riqueza de interagir com outros jovens na parte teórica do programa, jovens oriundos de outras organizações, com diferentes tipos de gestão de pessoas e de outros setores da economia (CLEMENTINO, 2013, p.46-47).

Neste ponto gostaríamos de ilustrar com o depoimento de um jovem aprendiz que iniciou seu curso de aprendizagem em uma instituição do Sistema S, permanecendo por um ano, mas optou em sair e entrar no mesmo curso oferecido por uma entidade filantrópica na mesma cidade:

Quando eu estava em uma instituição formadora do Sistema $S$, eu não sabia que existia uma lei do aprendiz, nunca nos foi apresentado. Quando 
entrei aqui, eles nas primeiras semanas começaram a estudar a lei com a gente. Por que lá na outra instituição, eles nunca falaram nada dos direitos e deveres da lei do aprendiz ( Grifo nosso para preservar a instituição, APREDIZ 01, 2013, ONG).

Para que o jovem aprendiz possa engajar-se no reconhecimento dos verdadeiros propósitos da aprendizagem, é necessário apresentar a ele os objetivos desse programa. Por meio de nossa experiência profissional, podemos inferir que um dos grandes problemas da Lei de Aprendizagem, não é apenas a falta de conhecimento por parte dos empresários, mas dos jovens e dos próprios instrutores. Os profissionais contratados para execução dos módulos dos cursos nas instituições formadoras, recebem suas apostilas prontas, sem uma preparação prévia, ou uma formação específica para que também possam estar conscientes da relevância desse projeto, não tendo possibilidades de conscientizar seus alunos. Umas das ações necessárias e primordiais para o funcionamento dos verdadeiros propósitos dos cursos de aprendizagem, seria a formação continua dos instrutores, programas de conscientização das empresas parceiras e dos próprios funcionários para acolhimento dos jovens e acompanhamento contínuo do aprendiz, no período de seu contrato.

\section{Aproximações da portaria n. 615 as determinações das OMs e empresariado}

A Portaria n॰ 615 de 13 de dezembro de 2007, altera alguns dispositivos do decreto 5.598 de $1 \circ$ de dezembro de 2005 que regulamenta o Cadastro Nacional de Aprendizagem. As entidades formadoras inscrevem seus programas para serem aprovados e avaliados. Este é um instrumento do MTE, para manter a qualidade desse modelo de formação. Nesta Portaria, queremos dar enfoque às diretrizes gerais, estabelecidas as entidades para que possam elaborar seus programas.

Começamos nossas reflexões trazendo um dos primeiros itens, na qual é proposto: "A promoção da mobilidade no mundo de trabalho pela aquisição de formação técnica geral e de conhecimentos e habilidades específicas como parte do itinerário formativo a ser desenvolvido ao longo da vida" (BRASIL, 2007, s.p).

Podemos observar que este tópico adere ao discurso das OMs, já relatado no III Capítulo, através da análise do documento "Educação e formação ao longo da vida; uma ponte para o futuro", da UNESCO. No primeiro eixo temático desse documento a CEPAL, sugere que o Ensino profissional seja reformado, para que os trabalhadores se adéqüem as novas tecnologias, para mobilidade, evitando desemprego e desigualdade social.

Esse documento sugere que os trabalhadores devem estar inclusos na formação geral e profissional, compreendendo valores, conhecimentos, habilidades, competências e qualificações, que devam estar presentes ao longo da vida. São falas muitos aproximadas, ficando bastante claro, que o Brasil, adota em suas políticas educacionais os modelos e orientações internacionais, principalmente nos moldes da educação profissional. Esta OM traz orientações específicas à aprendizagem, salientando que "a cultura da aprendizagem deveria permitir a criação e manutenção de uma estrutura institucional que instalará a aprendizagem ao longo da vida e uma ampla participação na educação e na formação" (UNESCO, 1999, p.13-14). Para esta OM o ensino técnico e profissional, é um dos instrumentos mais poderosos para enfrentamento dos desafios aos desenvolvimentos dos países, pois auxilia os jovens trabalhadores a encontrarem uma posição enquanto membros produtivos de uma sociedade.

Neste mesmo item da diretriz regulamentadora da Lei de Aprendizagem, é colocado de forma sintética os termos: “ promoção da mobilidade no mundo do trabalho". Mas, no 
mesmo documento acima descrito, a UNESCO detalha possibilidades de obtenção para mobilidade. Para ela o estudo de línguas e tecnologias, aquisição de habilidades técnicas e pessoais, novos sistemas salariais e trabalhos independentes, dariam mais possibilidades aos trabalhadores transitarem pelo mercado de trabalho.

\section{Alterações dos dispositivos da Lei de Aprendizagem pela Portaria 723/12: aproximações com empresariado e OMs}

Nesta unidade gostaríamos de fazer uma aproximação entre as diretrizes curriculares atuais estabelecidas na Portaria 723/12, aos interesses do empresariado e determinações das OMs, mostrando a estreita relação nos discursos proferidos entre eles. Iniciamos nossa análise trazendo alguns fragmentos das diretrizes desta Portaria. No primeiro item está expresso o primeiro objetivo que se pretende alcançar, mas deixando margens inócuas de interpretação, como o:

a) desenvolvimento social e profissional do adolescente e do jovem, na qualidade de trabalhador e cidadão;

Neste primeiro item buscamos fundamentação teórica nos estudos de Frigotto, para entender o desenvolvimento profissional e pessoal de um aprendiz, na qualidade de cidadão. Mas o que é ser cidadão? A que se refere o conceito de cidadania? O conceito de cidadania, é um termo recorrente nos documentos nacionais e internacionais de educação profissional, mas não se faz claro. No Brasil, ele nasce em meio à constituição da sociedade pós-colonial, sem muita definição do que seriam os direitos do cidadão. Mesmo que formalmente saibamos que todos são cidadãos, as classes sociais possuem acessos diferenciados "aos bens necessários a sobrevivência... não asseguram direitos iguais para todos porque prevalece, na prática o princípio lokeano da propriedade privada" (FRIGOTTO e CIAVATTA, 2003, p.53), por isso o termo é tão fragilizado.

Este conceito está diretamente ligado a liberdade e igualdade individual, em uma sociedade coletiva, de direitos e auto-realização de potencialidades, dentro de uma sociedade política. Elucida ainda que:

Esta diz respeito à capacidade do homem, enquanto indivíduo real, recuperar em si o universal, o cidadão abstrato, a relação entre ele e o todo, a sociedade, em uma condição de co-pertencimento à sua condição de indivíduo e de cidadão (FRIGOTTO e CIAVATTA, 2003, p.57).

Mas vivemos em uma realidade, aonde os trabalhadores participam de diversos segmentos, que exigem competências para exercer a cidadania. Em relação ao trabalho, "a ênfase na cidadania recai sobre o cidadão produtivo, sujeito as exigências do mercado, onde o termo produtivo refere-se ao trabalhador mais capaz de gerar mais-valia" (op. cit, p.53). Voltando ao capítulo III, segundo os autores citados, é com a implementação do PLANFOR, que se instala o termo "cidadão produtivo". O que significa submeter-se as determinações do capital que vão ao sentido da subordinação e não da participação para o desenvolvimento de suas potencialidades. Sem uma determinação clara aos aprendizes, empresários e instrutores dos programas, este objetivo será a reprodução das determinações das OMs, já aderidas pela educação profissional brasileira. 
Este mesmo discurso pode ser visto no segundo documento da CEPAL, analisado no capítulo III, Equidade e Transformação Produtiva: um enfoque integrado. Neste, uma das principais propostas é a importância da cidadania para formação e competitividade dos trabalhadores. Para esta OMs cidadania é: responsabilidade social, transmissão de valores e formação democrática, através da aquisição de habilidades para melhor desempenho. Interessante ressaltar que o conceito de cidadania, para esta OM está completamente associado ao capital, ou seja, a garantia de direitos está atrelada apenas a produção, sem levar em consideração todos os outros âmbitos do ser humano.

Na seqüência destas diretrizes, são colocados os seguintes itens:

b) perfil profissional, conhecimentos e habilidades requeridas para o desempenho da ocupação objeto de aprendizagem e descritos na $\mathrm{CBO}$ (BRASIL, 2013, s.p).

Podemos observar em nossa pesquisa, que os programas oferecidos em cada região, atendem apenas as demandas locais. Os jovens não buscam os cursos por uma escolha vocacional, de acordo com suas potencialidades e habilidades, mas pelas oportunidades que suas cidades oferecem. Em cidades interioranas, como as observadas em nossa prática profissional, os aprendizes acabam tendo poucas opções. As vagas geralmente são voltadas para redes de supermercados, farmácias e comercio local. Neste ponto fica bastante, claro, mesmo que exposto em um texto não detalhado, que os programas de aprendizagem, têm como propósito a formação para o objeto específico dos ofícios das empresas ofertantes. Hoje, sabemos que não existe uma pré-seleção que encaminhe os jovens para vagas adequadas ao seu perfil profissional, mas para as necessidades do mercado de trabalho local. Abaixo ilustramos essa realidade com o depoimento de um dos aprendizes, que evadiu do curso de uma entidade do Sistema S:

$\mathrm{Na}$ verdade eu era aprendiz no Sistema $\mathrm{S}$, mas por estar estudando, não queria trabalhar onde eu estava trabalhando, em um supermercado, daí eu sai do curso, pois lá os cursos eram só para supermercados. Uma pessoa muito amiga minha, me falou pra fazer aprendizagem em administração aqui neste instituto. No Sistema $S$ a parte técnica é totalmente focada, é bem profundo, você aprende mesmo como é o processo de um supermercado, mas é muito técnico. Aqui eles avaliam se você se dedicou nas aulas, não faltou, sua freqüência e postura. $\mathrm{O}$ que o mercado cobra eles nos cobram, uma postura enquanto pessoas e profissionais aprendizes. (APRENDIZ 06, 2013, COMUNICAÇÃO ORAL).

Esta fala ilustra, uma realidade pré-determinada pelas próprias diretrizes curriculares da Lei de Aprendizagem, de que sejam atendidas as "potencialidades do mercado local e regional de trabalho e as necessidades dos empregadores dos ramos econômicos para os quais se destina a formação profissional"(BRASIL, 2013,s.p). Esta, também é uma determinação decorrente das OMs. Na análise do documento Educação e conhecimento: eixo da transformação produtiva, no capítulo III, a CEPAL em 1997, criticava os países que não se adequavam as necessidades do mercado e colocava que os problemas da capacitação nos países da América Latina não eram apenas referentes às vagas, mas principalmente a inadequação da oferta, que deveriam atender as reais necessidades das empresas. Assim a Lei de Aprendizagem, adere as reformulações da formação profissional do setor produtivo.

Outra diretriz, que regulamenta a Lei de aprendizagem é o: 
e) ingresso de pessoas com deficiência e de adolescentes e jovens em situação de vulnerabilidade social nos programas de aprendizagem, condicionado à sua capacidade de aproveitamento e não ao seu nível de escolaridade; e

f) direitos humanos, com enfoque no respeito à orientação sexual, raça, etnia, idade, credo religioso ou opinião política (BRASIL, 2013, s.p).

Esta diretriz adota as recomendações estipuladas em 1999, no eixo: o ensino técnico profissional para todos, publicado pela UNESCO. Neste item ela sugere que a educação profissional deverá ser direcionada principalmente aos grupos marginalizados, em vulnerabilidade social. Também deverá levar em conta as desigualdades de gênero, promovendo ações de capacitação à todos. Em relação aos deficientes, tem um discurso muito próximo das Oms, ou seja, que sejam realizados ações para aperfeiçoar a inserção destes jovens deficientes ou vulneráveis, dentro de suas potencialidades, mas estimulando seu potencial. De maneira resumida, a Lei da Aprendizagem, segue mesma ideologia vigente por eles, utilizando em muitos momentos a mesma terminologia usada.

\section{Considerações finais}

Os discursos adotados pelas práticas educativas da educação para o trabalho, assim como as propostas da Lei do Aprendiz, reafirmam, mesmo depois de tantas alterações em suas portarias e decretos, algumas práticas sociais mediadoras, para o desenvolvimento econômico. Este modelo de Educação Profissional, patrocinado em grande parte pelo Banco Mundial e Banco Interamericano de Desenvolvimento, são aceitos de maneira subordinada, pelos governos e empresários. Estes, não se constituem em modelos que emancipam a classe trabalhadora, apenas "subordina-se ao ideário do mercado e do capital e de um modelo de desenvolvimento excludente, concentrador de renda e predatório"(FRIGOTTO, 2001, p.80).

Não podemos aferir apenas as limitações da Lei de Aprendizagem, pois percebemos no decorrer deste estudo, os benefícios que ela emerge à muitos jovens. Mas as influências e a subordinação da Lei, suas diretrizes e das próprias entidades formadoras, ao atendimento das necessidades do capital são concretas. Mesmo nas ONGs, que atuam na luta pelo ensino público de qualidade, buscando os interesses das classes menos favorecidas. Os projetos provindos das entidades filantrópicas possuem ações relevantes, principalmente as voltadas para as crianças e adolescentes, mas fica evidente sua limitação se forem avaliados os sucessos em relação aos inúmeros projetos abertos e extintos posteriormente. Pouca estrutura física e falta de recursos humanos, são uma das maiores dificuldades desse segmento. No Brasil elas apareceram em números assustadores por todo o país. Mas, infelizmente o incentivo financeiro, de muitas delas, provém de parcerias internacionais e de empresários locais, com interesses políticos:

Foram assim criadas ONGs de alcance internacional que serviriam como canais de apoio, investimento ou troca, que seriam financiadas por agências multilaterais e por grandes corporações. Enquanto essas primeiras ONGs tinham a total anuência e, muitas vezes, a supervisão de seus governos, entidades similares foram surgindo a partir de iniciativas independentes da sociedade civil. A grande maioria das ONGs, como as percebemos hoje, foram, não só no Brasil mas em todo o mundo, uma 
resposta da sociedade civil ao vácuo criado pelo desenvolvimentismo.(ÁLVARES, 2001, p. 1).

Este fenômeno é recente estando associado às ações do Banco Mundial em relação Terceiro Mundo, esta proposta aliava intenções de voluntariado a fins econômicos. Mesmo no segmento que busca a luta dos interesses das classes sociais, menos favorecidas, tem suas ações financiadas pelas OMs e pelo empresariado.

Em relação à formação, a alocução proferida de educação polivalente, na verdade, acaba por adestrar e acomodar os trabalhadores, tornando um "cidadão mínimo, que pensa minimamente e reage minimamente" (FRIGOTTO, 2001, p. 80). As portarias que regulamentam a Educação Profissional, são evidentemente pautadas no ideário do capital, com formação fragmentada, que possibilidade de tornar seus trabalhadores empregáveis, sem garantia de direitos, cidadania e obtenção de uma profissão.

Frigotto (2001) salienta que esta é uma estratégia do BM, para os países periféricos, tendo como orientações pedagógicas o eixo "a adaptação e confirmação do trabalhador, no plano psicofísico e emocional, às novas bases materiais, tecnológicas e organizacionais de produção. Assim a CNI, representa no Brasil, o ideário do BM. Seu plano pedagógico adota as terminologias como: conhecimento, atitudes, competitividade, adotado pelas OMs, tornando-se a perspectiva pedagógica do governo para educação básica e profissional.

\section{Referências}

BENDRATH, E.A; GOMES, A.A. Estado, políticas públicas e organismos internacionais: a educação no foco do debate. InterMeio: Revista do Programa de Pós-Graduação em Educação. Campo Grande, MS,v.16, n.32, p.157-171, jul./dez. 2010

BRASIL. Lei da Aprendizagem. Lei no 10.097, de 19 de dezembro de 2000. Brasília/DF, 2000.

Decreto n5.598/2005. Brasília: Diário oficial da União, 2005.

.Manual da aprendizagem: o que é preciso saber para contratar o jovem aprendiz - 3. ed. - Brasília: MTE, SIT, SPPE, ASCOM, 2009.

Decreto Lei no 8.621, de 10 de janeiro de 1946. Disponível em < http://www.planalto.gov.br/ccivil_03/decreto-lei/1937-1946/Del8621.htm.

Decreto Lei no4.4048, de 2 de janeiro de 1942. Disponível em < http://www.planalto.gov.br/ccivil_03/decreto-lei/1937-1946/Del4048.htm>.

BUIAR,C.J; GARCIA,N.MD. Lei do Jovem Aprendiz: as séries metódicas e suas implicações na formação técnico-profissional do trabalhador. In: I Seminário Nacional de Educação Profissional e Tecnológica, 1, Belo Horizonte- MG. Anais do I SENEPT. Belo Horizonte: CEFET, 2008. Disponível em < http://www.senept.cefetmg.br/galerias/Arquivos_senept/anais/terca_tema6/TerxaTema6Art igo18.pdf >. Acesso em 05 de janeiro de 2014.

CLEMENTINO, J.V. Aprendizagem Profissional: a lei que promove o trabalho descente para juventude e desenvolvimento econômico e social no Brasil. IPEA, Brasília, v.55, p.45 a 50, ago.2013. 
CIAVATTA, M; FRIGOTTO, G. Pronunciamento da Associação Nacional de PósGraduação e Pesquisa em Educação / Anped - GT Trabalho e Educação. Apresentado na Reunião da SEMTEC/MEC, Brasília, 18 de dezembro de 2003. Disponível em http://www.anped.org.br/ representacoesanped 2004.pdf.

CNI.Rumo ao crescimento: a visão industrial --- sumário executivo. Rio de Janeiro: CNI, 1994.

CUNHA, L. A. O ensino profissional na irradiação do industrialismo. 2. ed. São Paulo: UNESP; Brasília, DF: FLACSO, 2000.

FRIGOTTO, G. Educação e trabalho: bases para debater a educação emancipadora. Revista Perspectiva, Florianópolis, v.19, n.1, p.71-87, jan./jun, 2001.

FRIGOTTO, G; CIAVATTA, M. Educar o trabalhador cidadão produtivo ou ser humano emancipado? Trabalho, educação e saúde, Rio de Janeiro, v.1, p. 45-60, 2003.

MELO, A. A educação básica e formação profissional na visão dos empresários brasileiros. Educação e Sociedade, Campinas, v.30, n.108, p.893-914, out.2009. Disponível em <http://www.scielo.br/pdf/es/v30n108/a1330108.pdf>. Acesso em: 10 de outubro de 2013.

MINISTÉRIO DO TRABALHO. Portaria no 723, de abril de 2012. Disponível em: $<$ http://portal.mte.gov.br/data/files/8A7C816A36A27C140137709B066818B2/Portaria\%2 0MTE\%20n\%C2\%BA723,\%20de\%2023\%20de\%20abril\%20de\%202012.pdf>.

OLIVEIRA, R. Empresariado industrial e a educação brasileira: qualificar para competir ? São Paulo: Cortez, 2005. Alínea, 2006.

Agências multinacionais e educação profissional brasileira. Campinas:

ORGANIZAÇÃO INTERNACIONAL DO TRABALHO (OIT). A OIT e desemprego de jovens. Disponível em: $<$ http://www.oitbrasil.org.br/prgatv/prg_esp/emp_form_jov.php>. Acesso em: 16 jul. 2013.

Tendências Mundias de Emprego 2013. Disponível em: $<$ http://www.oit.org.br/content/desemprego-mundial-aumenta-novamente-mas-comgrandes-diferencas-regionais>. Acesso em: 09 de out. de 2013.

PIETRO, M. S. Z. Direito Administrativo. 24. ed. São Paulo: Atlas, 2011.

POCHAMANN, M. A batalha pelo primeiro emprego: a situação atual e as perspectivas do jovem no mercado de trabalho brasileiro. $1^{\text {a }}$ ed. São Paulo: Publischer, 2000.

ROCHA, E. A aprendizagem é vantajosa para a empresa. Depoimento. Disponível em: < http://www.buscajovem.org.br/noticias/pesquisa-aponta-vantagens-para-empresas-quecontratam-aprendizes>.

VIRIATO, J. P.V. O PLANFOR e a Educação de Jovens e Adultos Trabalhadores: A Subalternidade Reiterada. 2001. Dissertação (Mestrado em Educação) - Universidade Federal Fluminense, Niterói. 


\section{NOTAS}

${ }^{1}$ Mestranda em educação pela Unicentro, professora colaboradora do Departamento de Pedagogia da UNICENTRO.

2 Phd em Educação epal Universidade de Urbino na Itália, doutor em Educação pela UNICAMP, professor tiutlar do departamento de Pedagogia da UNICENTRO>

$3 \mathrm{O}$ nascimento das entidades sem fins lucrativos está vinculado a igreja, surgindo da necessidade de auxiliar os necessitados. Historicamente as ONGs segundo Tachizawa (2004) nascem na época do regime militar, período onde a sociedade brasileira convive ao mesmo tempo com um governo autoritário e uma industrialização crescente. As primeiras Organizações não Governamentais sem fins lucrativos eram conceituadas como grupos sociais de base que buscavam melhorias na qualidade de vida da população. Elas eram formadas por grupos de fiéis, que faziam visitas aos doentes e aos hospitais, mas com o aumento crescente deste tipo de entidade, o governo Getúlio Vargas em 1935, por meio de uma lei federal, cria a "declaração de utilidade pública"1, a fim de extinguir as entidades desonestas.

${ }^{4}$ Segundo o MTE (2013), o CBO "tem por finalidade a identificação das ocupações no mercado de trabalho, para fins classificatórios junto aos registros administrativos e domiciliares. Os efeitos de uniformização pretendida pela Classificação Brasileira de Ocupações são de ordem administrativa e não se estendem as relações de trabalho", podendo ser visualizado na integra todas as funções e sua descrições, no site do MTE: www.mtecbo.gov.br.

${ }^{5}$ Os Arcos ocupacionais não serão anexados, pela extensão do arquivo. Para visualização do documento, consultar o site do MTE, anexo 1, do Manual de Aprendizagem. Disponível em < http://www3.mte.gov.br/politicas_juventude/aprendizagem_pub_manual_aprendiz_2009.pdf >.

${ }^{6}$ Não colocaremos o Catálogo em anexo nessa pesquisa, pelo sua extensão, mas ele pode ser visualizado pelo site do MTE, pelo endereço: http://portal.mte.gov.br/politicas_juventude/2012.htm, conforme determina a Portaria n$^{\circ}$ 723, de 23 de Abril de 2012.7.

${ }^{7}$ O Cadastro Nacional de Aprendizagem é uma plataforma do MTE, aonde as entidades formadoras em formação profissional, interessadas em executar programas de aprendizagem devem ter seus registros feitos. Esta foi uma maneira que o MTE, encontrou de supervisionar as entidades, buscando a qualidade nesse modelo de qualificação.

${ }^{8}$ Os Arcos ocupacionais não serão anexados, pela extensão do arquivo. Para visualização do documento, consultar o site do MTE, anexo 1, do Manual de Aprendizagem. Disponível em< http://www3.mte.gov.br/politicas_juventude/aprendizagem_pub_manual_aprendiz_2009.pdf>.

${ }^{9}$ A Confederação Nacional das Indústrias, é o órgão que representa as indústrias brasileiras, defendo seus interesses.

${ }^{10}$ Administração Indireta é um modelo de administração de forma descentralizada.

Recebido: fevereiro-14 Aprovado: julho-14 